Vol. 5 (1), $\mathbf{n}^{0} 1.2020$, janeiro/julho de 2020.

\title{
Como efetivar a tutela e a proteção da mulher frente à criação de novas legislações protecionistas?
}

\section{Victória Maria Melo dos Santos ${ }^{(1)}$; Mariana Tereza Cézar Cavalcante ${ }^{(2)}$; Márcio Oliveira Rocha ${ }^{(3)}$.}

${ }^{(1)}$ Estudante e Bolsista de Iniciação Científica (PIBIC); Universidade Estadual de Alagoas; Arapiraca/Alagoas; melo.victoria@icloud.com; ${ }^{(2)}$ Estudante; Universidade Estadual de Alagoas; maracezar1@ @otmail.com; ${ }^{(3)}$ Professor Orientador; Universidade Estadual de Alagoas; marciorocha50@ hotmail.com.

Resumo - A violência contra a mulher consiste em um grave problema que deve ser debatido e enfrentado principalmente pelos órgãos governamentais e pela sociedade. Embora atualmente existam leis e programas que defendam os direitos das mulheres, os índices de violência não diminuem significativamente, ou seja, há muito mais a ser feito. O presente trabalho tem o intuito de apontar a escassa aplicação de políticas públicas em prol do combate à violência contra a mulher, bem como esclarecer a ineficácia do atendimento humanizado às vítimas de importunação sexual. Outrossim, diante das diversas leis existentes, é necessário compreender porque as mesmas não são suficientes para combater o tipo de violência supramencionado. Do mesmo modo, é importante entender como funcionam, quais os problemas no momento de atuar na sociedade e, principalmente, identificar quais suas limitações e os erros cometidos. A problemática da importunação sexual tem se tornado um dos temas mais debatidos contemporaneamente, havendo maiores preocupações na criação de leis e na implementação de políticas públicas de amparo e assistência à mulher vítima. Ante o exposto, esse trabalho tem a pretensão de contribuir com a divulgação e a acessibilidade de informações para a população acerca dos meios de recorrer às medidas de prevenção, combate e amparo às vítimas de importunação sexual, bem como sanar dúvidas sobre o que é necessário para obter o devido atendimento pelos órgãos responsáveis.

Palavras-chave: violência; importunação sexual; políticas públicas.

\begin{abstract}
The violence against women is a serious problem that must be debated and faced mainly by government agencies and society. Although there are currently laws and programs that defend women's rights, the rates of violence do not decrease significantly, meaning there is much more to be done. The present study aims to point out the scarce application of public policies to combat violence against women, as well as to clarify the inefficacy of humanized care for victims of sexual harassment. Also, in view of the various existing laws, it is necessary to understand why they are not sufficient to combat the types of violence mentioned above. In the same way, it is important to understand how they work, what problems they have in the moment of acting in society, and especially to identify their limitations and mistakes. The problem of sexual harassment has become one of the most debated issues at the moment, with greater concerns regarding the creation of laws and the implementation of public policies of protection and assistance to female victims. In view of the above, this work intends to contribute to the dissemination and accessibility of information to the population about the means of resorting to measures to prevent, combat and protect the victims of sexual harassment, as well as to answer questions about what is necessary to obtain due care by the responsible organs.
\end{abstract}

Keyword: violence; sexual harassment; publics politcs. 


\section{Introdução}

A violência contra a mulher envolve uma problemática bastante complexa, sobretudo, no aspecto dos meios de proteção às vítimas, a forma que são utilizados e de qual maneira que são concretizados. É sabido que diversas políticas públicas, leis e outros mecanismos foram criados com o intuito de proteger os direitos das mulheres, como, por exemplo, a implementação de Delegacias de Atendimento à Mulher que realizam ações de proteção às vítimas dos mais variados tipos de violência, bem como de investigação dos crimes e Centros de Referência À Mulher Em Situação de Violência, os quais executam ações de prevenção e acolhimento. Embora essas implementações tenham sido um grande avanço na proteção e no atendimento às mulheres, elas, assim como outros mecanismos utilizados no combate a essa espécie de violência, se deparam com diversos obstáculos, principalmente no que tange a sua efetivação. Não é suficiente a existência de aparatos legais para proteger às vítimas, se faz necessário que haja a execução de políticas públicas que visem prevenir, conscientizar e evitar que condutas de importunação sexual aconteçam constantemente no cotidiano feminino.

E é diante desse contexto que o presente trabalho procura expor como os órgãos na cidade de São José da Tapera atuam diante das ocorrências de importunação sexual, apesar de que esse crime tenha como vítima qualquer pessoa, é notório que na maioria dos casos a vítima seja uma mulher. Assim, a importunação sexual é mais uma violência que tem no sujeito passivo o gênero feminino.

Nesse contexto, mister se faz mencionar alguns pontos da Lei $n^{\circ} 13.718 / 18$ que criminaliza a conduta mais comum: masturbar-se em público. Antes da mencionada lei esse tipo de conduta era tratada como contravenção penal, a qual punia com multa quem importunava alguém de modo ofensivo ao pudor. Após a nova legislação, quem pratica ato libidinoso com o objetivo de satisfazer a própria lascívia ou de outrem poderá ser punido, tornando-se recluso e cumprindo pena de 1 (um) a 5 (cinco) anos. Não obstante essa lei seja muito importante e necessária, ela terá de enfrentar diversos problemas já existentes antes da sua criação, sendo um destes, a dificuldade de aplicação de mecanismos de proteção à mulher, por exemplo, a falta de elementos necessários à qualificação do atendimento oferecido à vítima. A falta de atendimento específico e humanizado, leva a exposição da vítima, visto que é comum que autoridades não deem credibilidade ao depoimento da mesma, sendo o resultado da debilidade dos órgãos responsáveis por atuar nas ocorrências de crimes contra a dignidade sexual.

Assim, o trabalho em questão tem como objetivos mostrar de que forma os crimes de importunação sexual são encarados pelos órgãos de proteção à mulher na mencionada cidade alagoana. Além disso, ressaltar quais os empecilhos enfrentados pelas políticas públicas e pelas leis no combate às condutas de violência à mulher, assim como a perspectiva de atuação dos órgãos após a supramencionada lei de importunação sexual.

\section{Procedimento metodológico}

A pesquisa fora realizada por meio de consulta em sites, bem como bibliografias e artigos, utilizando-se do método dedutivo. Além disso, também foi empregado o método qualitativo, através da coleta de dados no Fórum e no Centro Integrado de Segurança Pública situados na cidade de São José da Tapera. A coleta de dados teve por objetivo observar 
quantos casos de importunação sexual existem na cidade e como são tratados nos órgãos supramencionados e como o atendimento às vítimas é realizado.

\section{Resultados e discussão}

Nas visitas aos órgãos de São José da Tapera, notamos que no Centro Integrado de Segurança Pública há apenas um delegado plantonista, presente apenas nos dias de plantão, quais sejam, terça-feira e quarta-feira, tendo, portanto, um servidor incapacitado para atender as vítimas de importunação sexual na ausência do delegado, visto que há cerca de um mês condutas como esta têm se repetido constantemente e nada foi feito, até o momento, pela autoridade policial responsável. Há recusa de registrar boletim de ocorrência, inclusive, negando o direito às vítimas. É notória a falta de capacitação de profissionais deste centro de segurança pública.

Contudo, com base na pesquisa, nota-se a escassa tramitação de ações nesse sentido, bem como a pequena quantidade de registros de boletins de ocorrência, fato que se deve à falta de incentivo à denúncia. Nota-se que a falta de políticas públicas de amparo, incentivo e conscientização das vítimas interfere diretamente nesse resultado, contribuindo para a impunidade dos criminosos e encorajando a continuidade de tais condutas.

Anteriormente ao dia vinte e quatro de setembro de dois mil e dezoito, a conduta era considerada apenas contravenção penal (crime-anão, de acordo com Nelson Hungria), ou seja, possuía uma pena branda. Após ser sancionada a Lei 13.718/18, pelo Ministro Dias Toffoli, esta conduta passa a ter pena de reclusão de 1 (um) a 5 (cinco) anos, bem como passa a ser crime. Ademais, convém mencionar que a pena da aludida lei será aplicada independentemente do consentimento da vítima. Assim, a ação será pública incondicionada.

Nessa linha, é possível pontuar que os homens que se masturbarem ou ejacularem em mulheres em locais públicos serão enquadrados na Lei de Importunação Sexual. Casos como estes são muito comuns, conforme verificado pela pesquisa realizada e pela coleta de dados que constatou a existência desse tipo de ato na cidade de São José da Tapera, todavia, não são noticiados nem registrados.

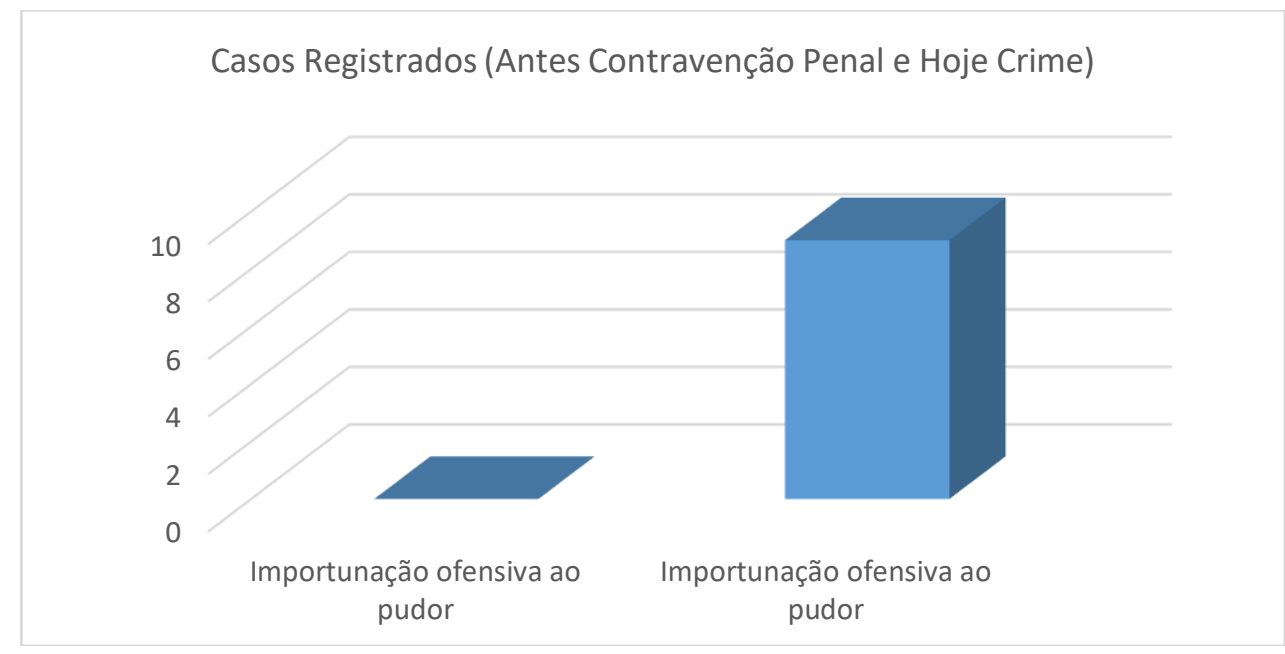


$\mathrm{Na}$ fase preparatória da pesquisa de campo em São José da Tapera, foi constatado que o número de casos é baixo, conforme o gráfico apresentado apenas 10 condutas foram tipificadas como importunação ofensiva ao puder, o que não é necessariamente bom, visto que a inexistência de registros não significa que não há casos dessas natureza, mas apenas que não foram denunciados, seja por medo, por falta de informação ou ausência de incentivo ou de políticas que auxiliem as vítimas quando estas necessitarem de ajuda para combater a violência sofrida. Além do mais, ressalta-se que na supramencionada cidade não há uma Delegacia de Atendimento a Mulher o que se torna mais um óbice no combate à violência contra a mulher no sertão alagoano.

Nota-se que durante o período em que a conduta era caracterizada como contravenção penal - pelo Decreto-Lei no. 3.688/41: art. 61. Importunar alguém, em lugar público ou acessível ao público, de modo ofensivo ao pudor. - não há casos registrados, visto que como anteriormente mencionado não havia Delegacia no município, bem como não havia sido inaugurado o Centro Integrado de Segurança Pública. Apesar do CISP ter sido inaugurado em dezembro de 2018, não houve registro de ocorrência, haja vista que o amparo às vítimas que desejam denunciar casos como este é praticamente inexistente na cidade.

A despeito do que fora apurado durante as visitas, cabe salientar que a impunidade, a falta de incentivo à denúncia e a constância dessas condutas, bem como o despreparo de autoridades "competentes", estão intimamente ligados à cultura machista a qual vivemos. Os depoimentos das vítimas são postos em descrédito, caracterizados como exagerados e duvidosos, sendo, o agressor, o que possui total razão diante da maioria esmagadora das autoridades policiais.

\section{Conclusão}

É cristalino que somente a criação de leis e de mecanismos de proteção à mulher não são suficientes para combater a violência sexual, é preciso que juntamente com as novas legislações haja uma "capacitação" ou mesmo a contratação de pessoas preparadas para atender as vítimas, para que assim as situações de violência e de atendimento precário às vítimas sejam combatidas de forma efetiva. Ademais, a falta de informação das vítimas de importunação sexual acerca das medidas de prevenção e dos meios que podem ser utilizados para combater essas condutas criminosas impossibilitam que essa problemática seja devidamente resolvida de forma que os direitos das mulheres sejam realmente protegidos.

Como anteriormente mencionado, as Delegacias de Atendimento à Mulher são tidas como grande avanço na proteção da mulher, uma vez que impulsiona o aumento de denúncias e amplia a discussão da violência contra a mulher ao expor a quantidade de violência existente para o público. No entanto, o que ocorre na cidade de São José da Tapera diverge, pois possui um servidor despreparado para atender as vítimas e não há uma Delegacia Especializada da Mulher, bem como não há servidoras para agir diante das situações as quais há importunação sexual e isso acaba por dificultar a concretização dos mecanismos de tutela dos direitos das mulheres.

De fato, a violência contra a mulher, em geral, consiste em um problema que encontra dificuldades de ser enfrentado e consequentemente diminuído por diversas razões. Dentre elas, a cultura machista que objetifica o gênero feminino e induz o agressor a agir com sentimento de posse, bem como a falta políticas que incentivem a vítima a denunciar e, 
sobretudo, o quase extinto amparo às mulheres que buscam denunciar em órgãos responsáveis, as quais são recebidas em situação de descrédito, sendo incentivadas a não seguir com a denúncia.

No entanto, ao visitar o Fórum da Comarca de São José da Tapera, restou claro que há, por parte do Exmo. Sr. Juiz Thiago Lopes, o interesse em atuar e efetivar projetos que combatam condutas que violem à mulher e conscientizem a população acerca do assunto, sobretudo o público jovem nas escolas do referido município do sertão alagoano, juntamente com os componentes deste trabalho. Fica claro que ações benéficas como as supramencionadas, encabeçadas pelo Exmo. Sr. Juiz, devem ser seguidas para que haja mudança nesse cenário misógino e machista que objetifica a mulher.

APOIO FINANCEIRO: Fundação de Amparo à Pesquisa do Estado de Alagoas - FAPEAL.

\section{Referências}

GROSSI, Patricia Krieger; TAVARES, Fabrício André; OLIVEIRA, Simone Barros de. A rede de proteção à mulher em situação de violência doméstica: avanços e desafios. Revista de pensamento e investigação social, páginas 267-280,2008.

HUNGRIA, Nelson. Comentários ao Código Penal: denominou de "crimes-anões" as contravenções penais. Disponível em: https://www.direito.ufmg.br/revista/index.php/revista/article/download/838/783. Acesso em 08 de outubro de 2018.

LIMA, Daniel. A conformidade penal da Lei 13.718/2018 e o crime de importunação sexual. Disponível em: https://canalcienciascriminais.com.br/crime-importunacao-sexual-2/. Acesso em: 05 de outubro de 2018.

LOPES JR., Aury; ROSA, Alexandre Morais da; BRAMBILLA, Marília; GEHLEN, Carla. O que significa importunação sexual segundo a Lei 13.781/18?. Disponível em: https://www.conjur.com.br/2018-set-28/limite-penal-significa-importunacao-sexual-segundolei-1378118. Acesso em: 05 de outubro de 2018.

VASCONCELLOS, Hygino. Como funciona a nova lei de importunação sexual. Disponível em: https://gauchazh.clicrbs.com.br/seguranca/noticia/2018/10/como-funciona-a-nova-lei-deimportunacao-sexual-cjmttusl501z401pivz74bhf7.html. Acesso em: 05 de outubro de 2018. 